\title{
Is the fossil record adequate?
}

Dr Andrew Smith, moderator for this debate, introduces the topic and the conflicting viewpoints that surround it.

\section{ANDREW SMITH}

Although the basic quality of the fossil record could be seriously questioned 100 years ago, this century has seen an enormous increase in our knowledge of the age and geographic distribution of fossils. The record is now easily good enough to show that fossil man was never a contemporary of the dinosaurs, and that living sauropod dinosaurs do not survive in the jungles of central Africa. At a certain coarse level of resolution, the fossil record provides a true and meaningful picture of the history of life.

Two independent lines of evidence suggest that we have arrived at a mature and stable appreciation of the history of life on Earth 1,2 , and there is evidence that, for the geological outcrops to which we have access, our appreciation of their fossil record is really very good $\frac{3-5}{2}$. Yet it is also evident that strong forces have continuously biased the fossil record, distorting and masking the biological patterns contained within (for example ref. 6).

The real question is not whether our knowledge of the biota from today's outcrop is good, but whether such outcrops cover a sufficient geographic and environmental range to provide us with reliable patterns. At what level of taxonomic and temporal resolution does the available fossil record provide a true and accurate picture?

Nowhere is argument over the adequacy of the fossil record thrown into sharper focus than over the question of reconstructing phylogenetic relationships. That fossil taxa ought to be included in data matrices together with extant taxa for phylogenetic analysis is no longer contentious. However, opinion remains sharply divided as to how best to use associated temporal (stratigraphic) information.

Some think that the order of stratigraphic appearance of species in the fossil record should play a central role in phylogenetic tree-building. In such cases stratigraphic order is used from the outset to influence and direct branching relationships by maximizing the congruence between the age of a species' first occurrence in the fossil record and how early it branches from a phylogenetic tree.

Others see stratigraphy as irrelevant to phylogeny, and are happy to dismiss mismatches between the fossil record and cladistic hierarchy, no matter how striking, as a result of an inadequate fossil record. The role of stratigraphy is then restricted to post hoc dating of branching events.

In between are those that use stratigraphic data for fine tuning phylogenies initially constructed from morphological or genetic information. It is therefore not the value of stratigraphic information that is in question, but when and if that information ought to be brought into play when reconstructing phylogenetic history.

\section{Andrew Smith \\ Natural History Museum, London, UK}

\section{References}

1. Foote, M. Sampling, taxonomic description, and our evolving knowledge of morphological diversity. Paleobiology 23, 181-206 
(1997).

2. Benton, M.J. The quality of the fossil record of the vertebrates. in The adequacy of the fossil record (Donovan S.K. \& Paul C.R.C. eds) 269-303 (John Wiley, New York, 1998).

3. Foote, M. \& Raup. D.M. Fossil preservation and the stratigraphic ranges of taxa. Paleobiology 22, 121-140 (1996).

4. Paul, C.R.C. \& Donovan, S.K. An overview of the completeness of the fossil record. in The adequacy of the fossil record (Donovan S.K. \& Paul C.R.C. eds) 111-131 (John Wiley, New York, 1998).

5. Cheetham, A.H. \& Jackson, J.B.C. The fossil record of Cheilostome Bryozoa in the neogene and quaternary of tropical America: Adequacy for phylogenetic and evolutionary studies. in The adequacy of the fossil record (Donovan S.K. \& Paul C.R.C. eds) 227-242 (John Wiley, New York, 1998).

6. Signor, P.W. The geological history of diversity. Ann. Revs Ecol. System. 21, 509-539 (1985).

Nature (C Macmillan Publishers Ltd 1998 Registered No. 785998 England. 